\title{
Study of Cation Distribution of Mn-Zn Ferrites
}

\author{
S. M. Attia \\ Phys. \& Chem. Department, Faculty of Education, Kafr El-Shiekh, Egypt
}

A series of polycrystalline ferrite samples with the composition $\mathrm{Mn}_{x} \mathrm{Zn}_{1-\mathrm{x}} \mathrm{Fe}_{2} \mathrm{O}_{4}(x=0.0,0.25,0.5,0.75$, and 1.0) were prepared by the standard ceramic method. $X$-ray diffraction pattern confirm the existence of single phase of cubic spinel crystal structure with the lattice parameter ranges from $8.419 \AA$ (for $\mathrm{ZnFe}_{2} \mathrm{O}_{4}$ ) to $8.478 \AA$ (for $\mathrm{MnFe}_{2} \mathrm{O}_{4}$ ). This behavior was attributed to the ionic radii. The Mössbauer spectra were analyzed into two subspectra, one for the tetrahedral A-site and the other for the octahedral B-site. The Mössbauer parameters were determined and discussed for the studied system. Zn-ferrite shows a central paramagnetic phase $C$ while Mn-ferrite shows six line Zeeman pattern. The cation distribution was estimated from the analysis of the Mössbauer spectra as well as the $x$-ray diffraction patterns. The results showed that $\mathrm{Zn}$ ions occupy mainly A-site while $\mathrm{Mn}$ and Fe ions are distributed between $A$ - and $B$ - sites.

\section{Introduction:}

High initial magnetic permeability, low magnetic loss, and high electrical conductivity are the most advantages features of $\mathrm{Mn}-\mathrm{Zn}$ ferrite as the main category of soft magnetic materials. Therefore $\mathrm{Mn}-\mathrm{Zn}$ ferrites are mainly used as the cores for inductors, transformers, recording heads and in switch mode power supplies [1-5]. The properties of Mn-Zn ferrite depend mainly on the technique and conditions of preparation, which in turn affect the cation distribution over the tetrahedral $\mathrm{A}$-site and the octahedral $\mathrm{B}$-site. In this work the cation distribution and the physical properties of $\mathrm{Mn}_{\mathrm{x}} \mathrm{Zn}_{1-\mathrm{x}} \mathrm{Fe}_{2} \mathrm{O}_{4}$ were studied using the x-ray diffraction and Mössbauer spectroscopy.

\section{Experimental Techniques:}

Polycrystalline ferrites of the formula $\mathrm{Mn}_{\mathrm{x}} \mathrm{Zn}_{1-\mathrm{x}} \mathrm{Fe}_{2} \mathrm{O}_{4}$ (x $=0.0,0.25$, $0.5,0.75$, and 1.0 ) were prepared by the standerd ceramic method. Highly pure oxides were mixed together and ground for 4 hours by an electric grinding machine, and then the mixtures were presintered at $900^{\circ} \mathrm{C}$ for 5 hours in air. Each mixture was ground again for 4 hours more and pressed in a disc shape. 
Finally the discs were sintered at $1200^{\circ} \mathrm{C}$ in air for 5 hours. A disc from each sample was ground in order to get fine powders for $\mathrm{X}$-ray and Mössbauer effect measurements. $\mathrm{X}$-ray studies were carried out by X-ray difrractometer using radiation source $\mathrm{Cu}-\mathrm{K}_{\alpha}$ radiation $(\lambda=1.5405 \AA)$. The Mössbauer spectra were recorded at room temperature using ${ }^{57} \mathrm{Co}$ source in rhodium matrix, whereas metallic iron was used for calibration. The Mössbauer measurements were carried out at Al-Azhar University, Center for Materials Science Research \& Glass.

\section{Results and discussion:}

\subsection{X-ray Diffraction pattern}

Figure (1) shows the $\mathrm{X}$-ray diffraction patterns for the system $\mathrm{Mn}_{\mathrm{x}} \mathrm{Zn}_{1-\mathrm{x}} \mathrm{Fe}_{2} \mathrm{O}_{4}$. The patterns show the existence of only single phase of cubic spinel ferrites. The interplaner distances, $d$, Miller indices ( $h k l$ ), and relative intensities, $I / I_{o}$ (where $I_{o}$ is the maximum intensity) were recorded for each pattern. The results of crystal structure of the sample with $\mathrm{x}=0.0$ were found to be in good agreement with that obtained by JCPDS card (22-1012) for $\mathrm{ZnFe}_{2} \mathrm{O}_{4}$.

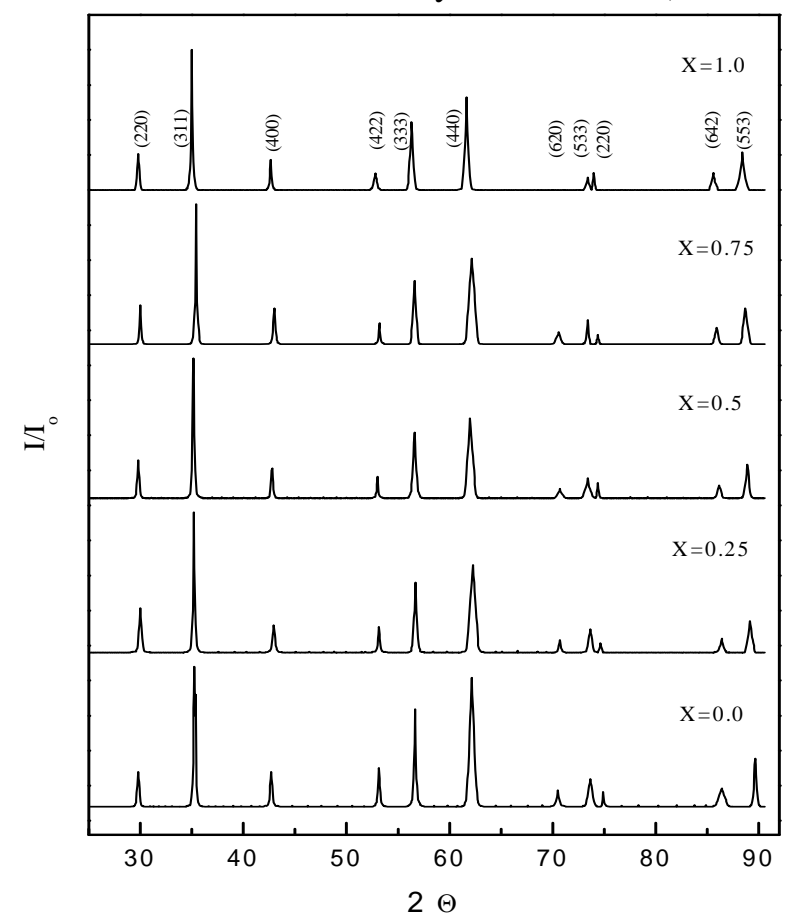

Fig. (1): X-ray diffraction pattern for $\mathrm{Mn}_{\mathrm{x}} \mathrm{Zn}_{1-\mathrm{x}} \mathrm{Fe}_{2} \mathrm{O}_{4}$ system. 
3.1.1. Lattice parameter, X-ray density and Crystallite Size:

In the case of cubic crystal structure, the lattice parameter, $a$, can be calculated using the following relation [7]

$$
\frac{1}{d_{h k l}^{2}}=\frac{h^{2}+k^{2}+l^{2}}{a^{2}}
$$

By plotting the value of $\left(h^{2}+k^{2}+l^{2}\right)$ versus $1 / d^{2}$, the value of the lattice constant, $a$, was determined for each sample. Fig. (2) shows the variation of the lattice constant, $a$, with the manganese content, $\mathrm{x}$. The results show that the lattice parameter increases with increasing $\mathrm{Mn}$ ion content. The increase of the lattice parameter can be attributed to the ionic radii of the ions. The value of the lattice constant for $\mathrm{ZnFe}_{2} \mathrm{O}_{4}$ was found to be $0.842 \mathrm{~nm}$ which is in good agreement with that obtained by JCPDS card where $a=0.844 \mathrm{~nm}$, while the value of lattice constant for $\mathrm{MnFe}_{2} \mathrm{O}_{4}$ was found to be $0.848 \mathrm{~nm}$.

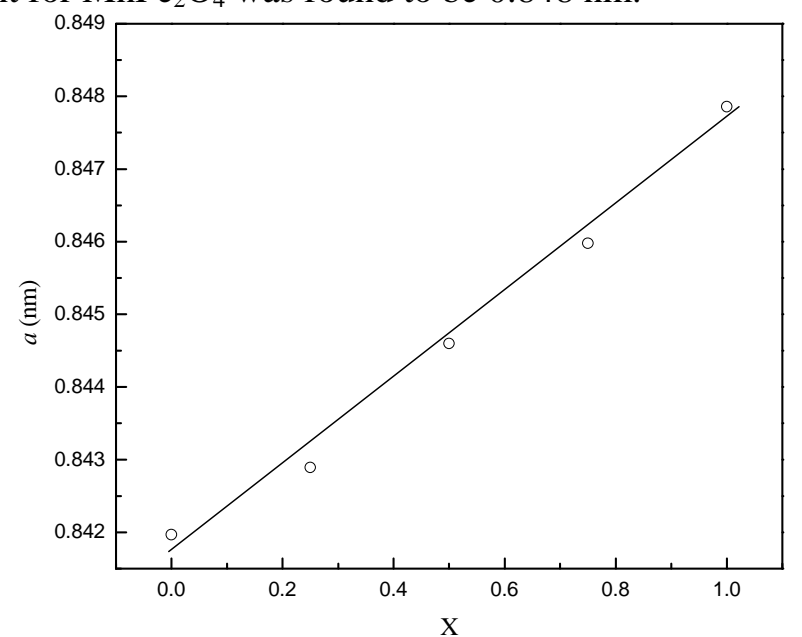

Fig. (2): The variation of the lattice constant, $a$, with $\mathrm{Mn}^{2+}$ ions content.

Since each primitive unit cell of the spinel structure contains 8 molecules, the value of the $\mathrm{X}$-ray density, $\mathrm{D}_{\mathrm{x}}$ was determined according to the relation,

$$
D_{x}=\frac{8 M}{N a^{3}}
$$

where $N$ is Avogadro's number $\left(=6.0225 \times 10^{23}\right.$ atom $\left./ \mathrm{mole}\right)$ and $\mathrm{M}$ is the molecular weight of the sample. Fig. (3) shows the variation of $D_{x}$ as a function of $\mathrm{Mn}$ ion contents. It is shown that $\mathrm{D}_{\mathrm{x}}$ decreases with increasing $\mathrm{x}$. The value of $\mathrm{D}_{\mathrm{x}}$ for $\mathrm{ZnFe}_{2} \mathrm{O}_{4}$ was found to be $5.365 \mathrm{gm} / \mathrm{cm}^{3}$, while for $\mathrm{MnFe}_{2} \mathrm{O}_{4}$ was 5.026 $\mathrm{gm} / \mathrm{cm}^{3}$. The decrease of $D_{x}$ with $\mathrm{Mn}$ ion content could be attributed to the atomic weight and the radii of constituent ions. 


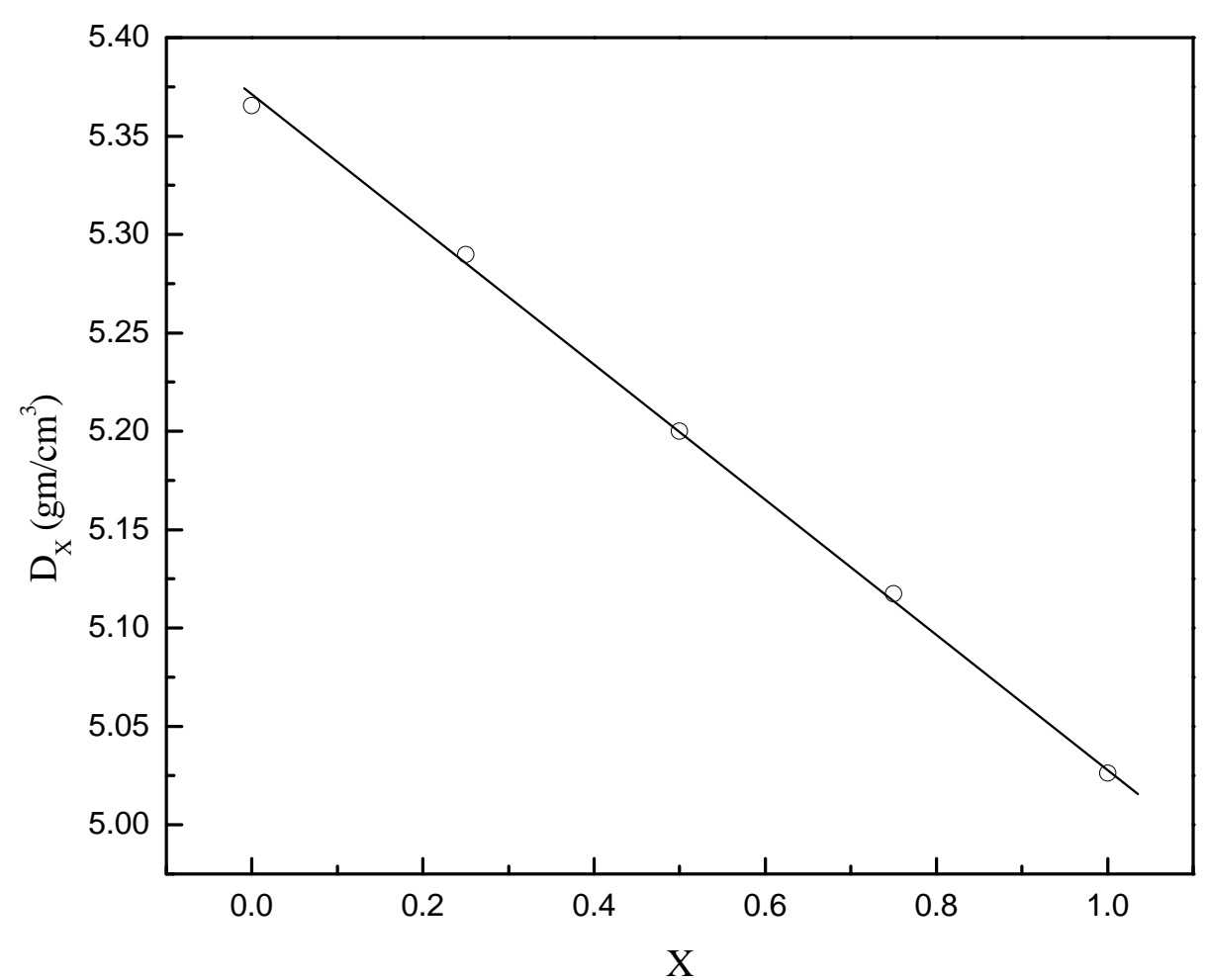

Fig. (3): The variation of the $\mathrm{X}$-ray density with $\mathrm{Mn}^{2+}$ ions content.

The size of the particles of the powder was determined using Scherrer equation [6].

$$
D_{h k l}=\frac{K \lambda}{B_{h k l} \cos \Theta}
$$

where $D_{\text {hkl }}$ is the mean dimension of the crystallites perpendicular to the plane (hkl), $\mathrm{B}_{\mathrm{hkl}}$ is the width at half-maximum intensity in radians, and $\mathrm{K}$ is constant that is commonly assigned the value of unity. The average value of the crystallites dimension for all powders was found to be $31.5 \mathrm{~nm}$.

\subsubsection{Estimation of the Cation Distribution:}

Spinel ferrite with formula $\mathrm{MeFe}_{2} \mathrm{O}_{4}$ contains two types of sites: tetrahedral site and octahedral sites. The distribution of the cations over these two sites can be expressed as [7]

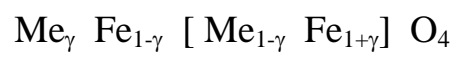


where the square practices include the ions at the octahedral sites, and $\gamma$ is a constant which can determine the cation distribution. For the system under investigation $\mathrm{Mn}_{\mathrm{x}} \mathrm{Zn}_{1-\mathrm{x}} \mathrm{Fe}_{2} \mathrm{O}_{4}$, the cation distribution can be expressed as

$$
\mathrm{Zn}_{\delta} \mathrm{Mn}_{\gamma} \mathrm{Fe}_{1-\gamma-\delta}\left[\mathrm{Zn}_{1-\mathrm{x}-\delta} \mathrm{Mn}_{\mathrm{x}-\gamma} \mathrm{Fe}_{1+\gamma+\delta}\right] \mathrm{O}_{4}
$$

Therefore, the mean radius of the ion at the tetrahedral site is given by

$$
r_{\text {tetr }}=\delta r_{Z n}+\gamma r_{M n}+(1-\gamma-\delta) r_{F e}
$$

and the mean radius of the ion at the octahedral site is given by

$$
r_{\text {oct. }}=\frac{1}{2}\left[(1-x-\delta) r_{Z n}+(x-\gamma) r_{M n}+(1+\gamma+\delta) r_{F e}\right]
$$

From the other hand, the mean radius of the ions at tetrahedral site and octahedral site is given by [8]

$$
\begin{aligned}
& r_{\text {tetr. }}=a \sqrt{3}(u-0.25)-R_{o} \\
& r_{\text {oct. }}=a\left(\frac{5}{8}-u\right)-R_{o}
\end{aligned}
$$

where $R_{o}$ is the radius of the oxygen ion (1.26 $\AA$ ) and $u$ is the oxygen parameter. Solving Eqns. $(6-9)$, both $\delta$ and $\gamma$ can be determined. Then the cation distribution can be estimated. Table (1) shows the estimated cation distribution for these samples.

Table 1: Estimated cation distribution for $\mathrm{Mn}_{\mathrm{x}} \mathrm{Zn}_{1-\mathrm{x}} \mathrm{Fe}_{2} \mathrm{O}_{4}$ using $\mathrm{X}$-ray results.

\begin{tabular}{|c|c|c||}
\hline Composition, $\mathrm{x}$ & Tetrahedral site & Octahedral site \\
\hline \hline 0.00 & $\mathrm{Zn}(0.84) \mathrm{Fe}(0.16)$ & $\mathrm{Zn}(0.16) \mathrm{Fe}(1.84)$ \\
\hline 0.25 & $\mathrm{Zn}(0.63) \mathrm{Mn}(0.16) \mathrm{Fe}(0.21)$ & $\mathrm{Zn}(0.12) \mathrm{Mn}(0.09) \mathrm{Fe}(1.79)$ \\
\hline 0.50 & $\mathrm{Zn}(0.42) \mathrm{Mn}(0.32) \mathrm{Fe}(0.26)$ & $\mathrm{Zn}(0.08) \mathrm{Mn}(0.18) \mathrm{Fe}(1.74)$ \\
\hline 0.75 & $\mathrm{Zn}(0.21) \mathrm{Mn}(0.48) \mathrm{Fe}(0.31)$ & $\mathrm{Zn}(0.04) \mathrm{Mn}(0.27) \mathrm{Fe}(1.69)$ \\
\hline 1.00 & $\mathrm{Mn}(0.64) \mathrm{Fe}(0.36)$ & $\mathrm{Mn}(0.38) \mathrm{Fe}(1.64)$ \\
\hline
\end{tabular}

\subsubsection{The Interionic Distances:}

The interionic distances (i.e. cation-anion distances at A-site, $d_{A L}$, and B-site, $d_{B L}$, together with the distance of closest anion-anion approach, tetrahedral edge, $d_{A E}$, and shared and unshared octahedral edges, $\left.d_{B E}, d_{B E U}\right)$ are calculated according to the following Eqns. [9]: 


$$
\begin{aligned}
& d_{A L}=a \sqrt{3}(u-0.25) \\
& d_{B L}=a\left(3 u^{2}-\frac{11}{4} u+\frac{43}{64}\right)^{1 / 2} \\
& d_{A E}=a \sqrt{2}(2 u-0.5) \\
& d_{B E}=a \sqrt{2}(1-2 u) \\
& d_{B E U}=a\left(4 u^{2}-3 u+\frac{11}{16}\right)^{1 / 2}
\end{aligned}
$$

The obtained values are listed in Table (2). It is clear that the values of $d_{A L}, d_{B L}, d_{A E}, d_{B E}$, and $d_{B E U}$ increase with increasing $\mathrm{Mn}$ ion content. This variation may be attributed to the substitution process and the cation distribution (Table (1).

The distance $L_{A}$ and $L_{B}$ between the magnetic ions at A-site and B-site respectively can be obtained where, $L_{A}=a \sqrt{3} / 4$, and $L_{B}=a \sqrt{2} / 4$ [10]. The obtained values of $L_{A}$ and $L_{B}$ are listed in Table 2. It is clear that $L_{A}$ and $L_{B}$ reflect the same behavior of $a$, where they increase with increasing $\mathrm{Mn}^{2+}$ ion content. This may be due to the expansion of the unit cell arising from the substitution of relatively larger $\mathrm{Mn}^{2+}$ ions instead of $\mathrm{Zn}^{2+}$ ions.

Table 2. The bond length of A-sites $d_{A L}$ and B-sites $d_{B L}$, the tetrahedral edge $d_{A E}$, the shared and unshared octahedral edges, $d_{B E}$ and $d_{B E U}$, and the hopping length at A-site $L_{A}$ and at B-site $L_{B}$ for each sample.

\begin{tabular}{|c||c|c||c|c|c||c|c||}
\hline \hline $\mathrm{X}$ & $d_{A L}(\AA)$ & $d_{B L}(\AA)$ & $d_{A E}(\AA)$ & $d_{B E}(\AA)$ & $d_{B E U}(\AA)$ & $L_{A}(\AA)$ & $L_{B}(\AA)$ \\
\hline 0.00 & 1.9723 & 2.0223 & 3.2209 & 2.7327 & 2.9818 & 3.6458 & 2.9768 \\
\hline 0.25 & 1.9752 & 2.0241 & 3.2256 & 2.7345 & 2.9851 & 3.6498 & 2.9800 \\
\hline 0.50 & 1.9800 & 2.0279 & 3.2333 & 2.7388 & 2.9912 & 3.6572 & 2.9861 \\
\hline 0.75 & 1.9839 & 2.0308 & 3.2398 & 2.7421 & 2.9962 & 3.6632 & 2.9910 \\
\hline 1.00 & 1.9891 & 2.0349 & 3.2482 & 2.7470 & 3.0029 & 3.6713 & 2.9976 \\
\hline \hline
\end{tabular}

\subsection{Mössbauer Spectra of the system $\mathrm{Mn}_{\mathrm{x}} \mathrm{Zn}_{1-\mathrm{x}} \mathrm{Fe}_{2} \mathrm{O}_{4}$}

The Mössbauer spectra of the system $\mathrm{Mn}_{\mathrm{x}} \mathrm{Zn}_{1-\mathrm{x}} \mathrm{Fe}_{2} \mathrm{O}_{4}$ within the velocity range -10 to $10 \mathrm{~mm} / \mathrm{s}$ are shown in Fig. (4). The obtained spectra for the samples with $x=0.0$ and 0.25 show central paramagnetic phase, $C$, only. The spectra for the sample with $\mathrm{x}=0.5$ shows a central paramagnetic phase $\mathrm{C}$, relaxed sextet subspectra combined with a week six line Zeeman pattern. The spectra for the samples with $\mathrm{x}=0.75$ and 1.0 show six line Zeeman patterns. The 
six line spectra for the samples with $\mathrm{x}=0.5,0.75$, and 1.0 were analyzed into two subspectra. The sharper pattern is due to $\mathrm{Fe}^{3+}$ ions at $\mathrm{A}$-site while the broader pattern is due to $\mathrm{Fe}^{3+}$ and $\mathrm{Fe}^{2+}$ ions at $\mathrm{B}$-site. The broadening of the $\mathrm{B}$-pattern is interpreted as being due to the distribution of hyperfine fields at B-site caused principally by random distribution of the cations at A-site [12]. The paramagnetic phase was analyzed into two quadrupole doublets due to $\mathrm{Fe}^{3+}$ ions at A-site, $\mathrm{C}_{\mathrm{A}}$, and $\mathrm{B}-$-site, $\mathrm{C}_{\mathrm{B}}$.

The existence of the paramagnetic phase $C$ in the Mössbauer spectra may be due to the fact that a fraction of Fe ions have few nearest neighbors which are magnetically possess ordered spins [12], but the existing of the sixline magnetic pattern is due to the superexchange interaction between the magnetic ions at A- and B-sublattices [13]. Statistical fluctuations in the distribution of the magnetic and non-magnetic ions are believed to be responsible for this behavior [14]. The existence of the quadrupole doublet, $\mathrm{C}_{\mathrm{A}}$, in the spectra could be attributed to randomization of cations with different charges and radii at A- and B-sites [15]. The Mössbauer spectra have been fitted in order to get the Mössbauer parameters. Some of the Mössbauer parameters are listed in Table 3.

Table 3. Mössbauer parameter for the system $\mathrm{Mn}_{\mathrm{x}} \mathrm{Zn}_{1-\mathrm{x}} \mathrm{Fe}_{2} \mathrm{O}_{4}$ obtained at room temperature.

\begin{tabular}{|c||c||c|c|c||}
\hline \hline $\mathrm{x}$ & Pattern & $\begin{array}{c}I S \\
(\mathrm{~mm} / \mathrm{s})\end{array}$ & $\begin{array}{c}\text { QS } \\
(\mathrm{mm} / \mathrm{s})\end{array}$ & $\begin{array}{c}\text { Relative area } \\
(\%)\end{array}$ \\
\hline \hline \multirow{2}{*}{1.00} & $\mathrm{~A}$ & 0.324 & 0.127 & $17 \pm 2$ \\
\cline { 2 - 5 } & $\mathrm{B}$ & 0.229 & 0.034 & $83 \pm 2$ \\
\hline \hline \multirow{2}{*}{0.75} & $\mathrm{~A}$ & 0.373 & 0.016 & $19 \pm 2$ \\
\cline { 2 - 5 } & $\mathrm{B}$ & 0.316 & 0.012 & $81 \pm 2$ \\
\hline \multirow{3}{*}{0.50} & $\mathrm{~A}$ & 0.097 & 0.042 & $4 \pm 2$ \\
\cline { 2 - 5 } & $\mathrm{B}$ & 0.216 & 0.054 & $50 \pm 2$ \\
\cline { 2 - 5 } & $\mathrm{C}_{\mathrm{A}}$ & 0.154 & 0.835 & $4 \pm 2$ \\
\cline { 2 - 5 } & $\mathrm{C}_{\mathrm{B}}$ & 0.122 & 0.501 & $42 \pm 2$ \\
\hline \hline \multirow{2}{*}{0.25} & $\mathrm{C}_{\mathrm{A}}$ & 0.018 & 0.516 & $14 \pm 2$ \\
\cline { 2 - 5 } & $\mathrm{C}_{\mathrm{B}}$ & 0.144 & 0.484 & $86 \pm 2$ \\
\hline \hline \multirow{2}{*}{0.00} & $\mathrm{C}_{\mathrm{A}}$ & 0.100 & 0.738 & $10 \pm 2$ \\
\cline { 2 - 5 } & $\mathrm{C}_{\mathrm{B}}$ & 0.108 & 0.356 & $90 \pm 2$ \\
\hline \hline
\end{tabular}




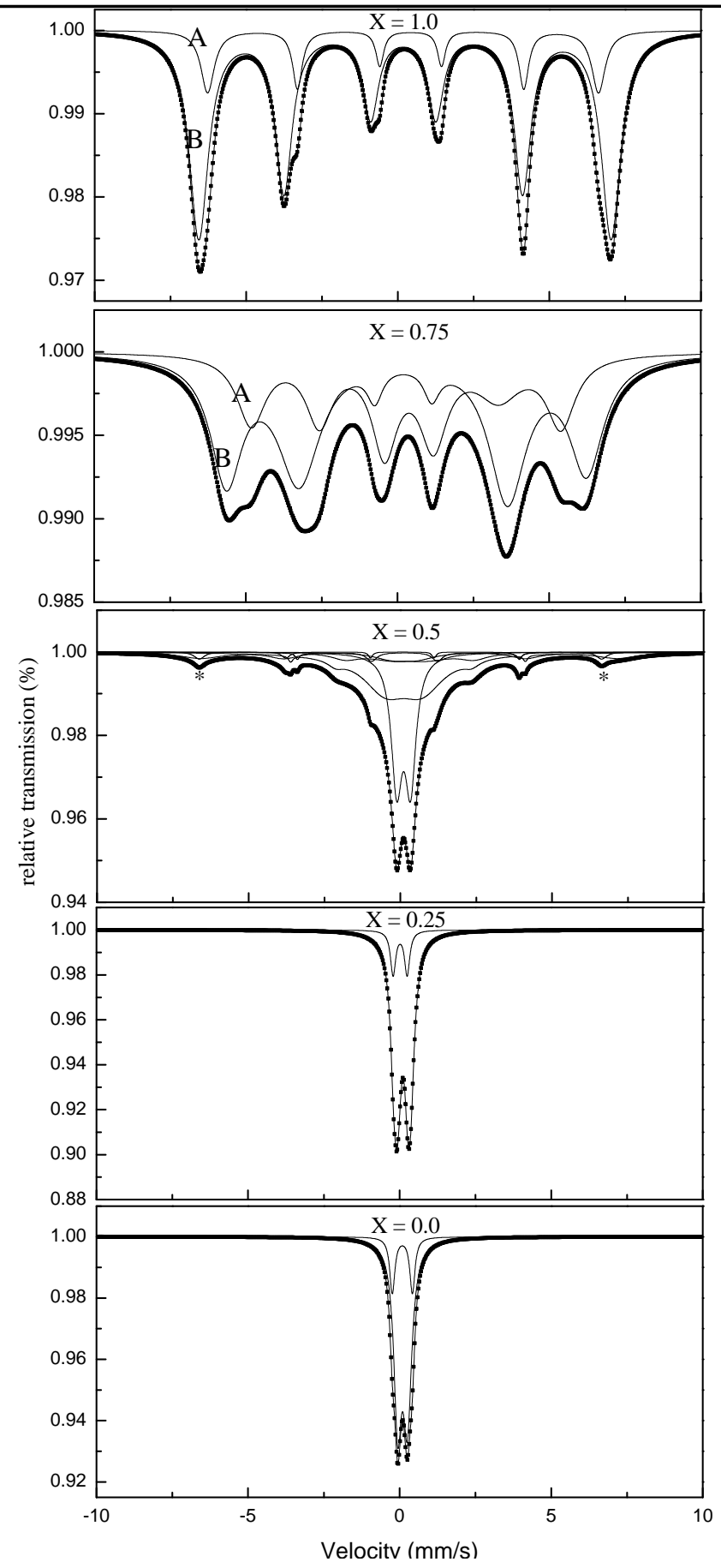

Fig. (4): Room temperature Mössbauer spectra of $\mathrm{Mn}_{\mathrm{x}} \mathrm{Zn}_{1-\mathrm{x}} \mathrm{Fe}_{2} \mathrm{O}_{4}$ system. 
The results show that the $\mathrm{Fe}^{3+}$ isomer shift values IS of A-sites $\left(I S_{A}\right)$ and B-sites $\left(I S_{B}\right)$ do not vary gradually with $\mathrm{Mn}$ ion content. Their values lie between 0.1 and $0.37 \mathrm{~mm} / \mathrm{s}$. The obtained values of the isomer shift are comparable with those reported previously for spinel ferrites and are characteristic of the high spin $\mathrm{Fe}^{3+}$ charge state [15]. The independence of the isomer shift on the $\mathrm{Mn}$ ion content means that the s-electron charge distribution of Fe ions is negligibly influenced by Mn substitution.

The values of the quadrupole shift $Q S$ of the A and B magnetic pattern for the sample with $\mathrm{x}=0.5,0.75$, and 1.0 are so small. This indicates that, in these samples, the local symmetry of the magnetic phase of A-sites is close to cubic while that of B-site is close to trigonal. The obtained $Q S$ values of the magnetic patterns A and B are comparable with that reported previously [12].

In ferrites, the doublet structure of Mössbauer spectra arises from the quadrupole interaction of ${ }^{57} \mathrm{Fe}$ nuclei located on octa points of the spinel lattice with the electric field gradient EFG at these points. The electric field gradient at Fe nucleus is due to the non-spherical distribution of the 3-d electrons of the ion itself as well as the charges on the neighboring ions [11]. For the case of $\mathrm{Fe}^{3+}$ ion which has a spherical distribution of the 3-d electrons, the EFG arises only from charges on the neighboring ions, while for the case of $\mathrm{Fe}^{2+}$ ion which has a nonspherical distribution of the 3d electrons, the EFG arises from $\mathrm{Fe}^{2+}$ ion itself as well as the charges on the neighboring ions. The quadrupole doublet splitting for the samples with $\mathrm{x}=0.0,0.25$, and 0.5 are listed in table 3 . It is shown that the values of $Q S$ are greater than 0.5. This confirms the existence of $\mathrm{Fe}^{2+}$ ion in these samples.

The magnetic hyperfine field, $\mathrm{H}$, for the samples with $\mathrm{x}=0.5,0.75$, and 1.0 are shown in Figure 5 as a function of $x$. It is well known that the magnetic hyperfine field arises from three different components: the first is the polarization of s-electrons by the magnetic moments of the d-electrons; the second is the dipolar fields of the surrounding magnetic ions and their distribution in A- and B-sites; and the third is the super transferred hyperfine fields arising from the magnetic moments of nearest neighboring cations [16]. Figure 5 show that the magnetic hyperfine field of $B-$ site, $H_{B}$, is greater than that of A-site, $\mathrm{H}_{\mathrm{A}}$, and both increase with $\mathrm{x}$. This behavior can be explained on the basis of the covalent character of the bond $\mathrm{Fe}^{3+}-\mathrm{O}^{2-}$ and changes in its length at $\mathrm{A}-$ and $\mathrm{B}-$ sites. The bond $\mathrm{Fe}^{3+} \mathrm{O}^{2-}$ is more covalent at $\mathrm{A}-$ site than that at $\mathrm{B}$-site, where the s-electron charge density at $\mathrm{A}$-site $\mathrm{Fe}^{3+}$ nucleus is larger $[17,18]$. This results in higher $H_{B}$ than $H_{A}$. The increase of the hyperfine magnetic fields with increasing of $\mathrm{Mn}^{2+}$ ion content is expected since $\mathrm{Mn}^{2+}$ ion has a magnetic moments of $5 \mu \mathrm{B}$, (the same as $\mathrm{Fe}^{3+}$ ion) while $\mathrm{Zn}^{2+}$ ion is non magnetic $(0 \mu \mathrm{B})$. The increase of $H$ with increasing of $\mathrm{Mn}^{2+}$ ion instead of $\mathrm{Zn}^{2+}$ 
ion indicates that $\mathrm{Zn}^{2+}$ ions are distributed over $\mathrm{A}-$ and $\mathrm{B}-$ site. The observed *signal (the two outer sextet with the hyper fine fields 42.6 and $41.1 \mathrm{~T}$ for $H_{B}$ and $H_{A}$ respectively) on the spectrum of the sample with $\mathrm{x}=0.5$ may be due to different substitution levels or crystallite size [19].

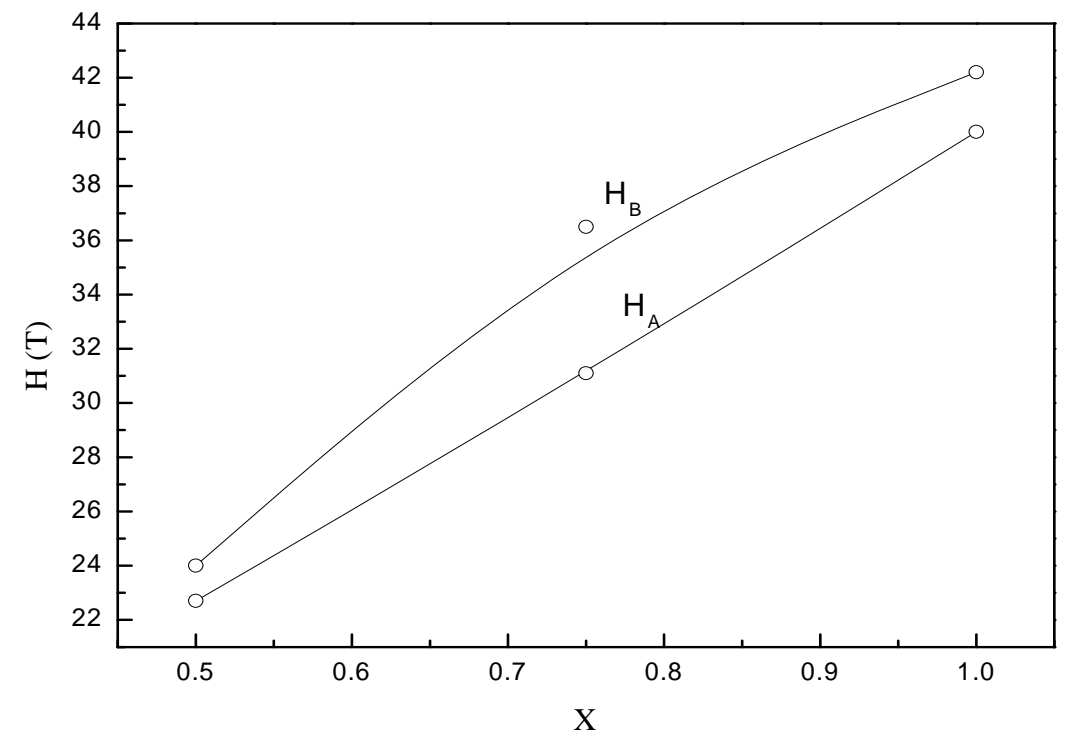

Fig. (5): The variation of the hyperfine magnetic fields $H_{A}$ and $H_{B}$ (for A- and $\mathrm{B}$ - site respectively) with $\mathrm{Mn}^{2+}$ ions content.

The distribution of Fe ion over $\mathrm{A}$ - and $\mathrm{B}$-sites is proportional to the relative area of $\mathrm{A}-$ and $\mathrm{B}-$ Mössbauer subspectra. Therefore, the cation distribution for the samples with $\mathrm{x}=0.0$ and 1.0 can be determined. On the light of site preference for each cation, their distribution over A- and B- site can be estimated. The estimated cation distribution for all samples using the Mössbauer spectra is shown in table 4. It is shown that the obtained cation distribution from Mössbauer spectra is closed to that obtained from X-ray diffraction pattern.

Table 4. The estimated cation distribution using Mössbauer parameters.

\begin{tabular}{||c||c|c||}
\hline Composition, $x$ & Tetrahedral site & Octahedral site \\
\hline \hline 0.00 & $\mathrm{Zn}(0.8) \mathrm{Fe}(0.2)$ & $\mathrm{Zn}(0.2) \mathrm{Fe}(1.8)$ \\
\hline 0.25 & $\mathrm{Zn}(0.6) \mathrm{Mn}(0.12) \mathrm{Fe}(0.28)$ & $\mathrm{Zn}(0.15) \mathrm{Mn}(0.13) \mathrm{Fe}(1.72)$ \\
\hline 0.50 & $\mathrm{Zn}(0.4) \mathrm{Mn}(0.34) \mathrm{Fe}(0.26)$ & $\mathrm{Zn}(0.1) \mathrm{Mn}(0.16) \mathrm{Fe}(1.74)$ \\
\hline 0.75 & $\mathrm{Zn}(0.2) \mathrm{Mn}(0.42) \mathrm{Fe}(0.38)$ & $\mathrm{Zn}(0.05) \mathrm{Mn}(0.33) \mathrm{Fe}(1.62)$ \\
\hline 1.00 & $\mathrm{Mn}(0.66) \mathrm{Fe}(0.34)$ & $\mathrm{Mn}(0.34) \mathrm{Fe}(1.66)$ \\
\hline
\end{tabular}




\section{Conclusions:}

A series of Polycrystalline ferrites $\mathrm{Mn}_{\mathrm{x}} \mathrm{Zn}_{1-\mathrm{x}} \mathrm{Fe}_{2} \mathrm{O}_{4}(\mathrm{x}=0.0,0.25,0.5$, 0.75 , and 1.0) were prepared by the standard ceramic method. The crystal structure of all samples are cubic spinels. The lattice parameter, $a$, increases with increasing $\mathrm{Mn}$ ion content; $a=8.419 \AA$ for $\mathrm{ZnFe}_{2} \mathrm{O}_{4}$ and $=8.478 \AA$ for $\mathrm{Mn}$ $\mathrm{Fe}_{2} \mathrm{O}_{4}$. The average crystallite size was $31.5 \mathrm{~nm}$. The theoretical density decrease with increasing $\mathrm{Mn}$ ion content. The cation distribution was estimated by $\mathrm{x}$-ray diffraction and Mössbauer spectra for all sample. The estimated cation distribution showed that $\mathrm{Zn}$ ion is mainly distributed over A-site while Fe and Mn ions are distributed over A- and B-site. The Mössbauer spectra for the samples with $\mathrm{x}=0.0$ and 0.25 show central paramagnetic phase only. The spectra for the sample with $\mathrm{x}=0.5$ shows a central paramagnetic phase combined with weak six line Zeeman patterns. The spectra for the samples with $\mathrm{x}=0.75$ and 1.0 show six line Zeeman pattern only. The decrease of the hyperfine fields with increasing of $\mathrm{Zn}$ ion content was attributed to the decrease of the exchange interaction.

\section{References:}

1. R. V. Mangalaraja, S. Ananthakmar, P. Manohar, F.D. Gnanam, M. Awano, Mater. Sci. Eng. A, 367, 301 (2004).

2. S.H. Chen, S.C. Chang, I.N. Lin, J. Magn. Magn. Mater. 209, 193 (2000).

3. M. Schaefer, G. Dietzmann, H. Wirth, J. Magn. Magn. Mater. 101, 95 (1991).

4. M. Rozman, M. Drofenik, J. Am. Ceram. Soc. 81 (7), 1757 (1998).

5. J. A. T. Taylor, S.T. Reczek, A. Rosen, Am. Ceram. Soc. Bull. 74 (4) 91 (1995).

6. H. P. Klug and L. E. Alexander "X-ray Diffraction Procedures", John Wiley New York (1974).

7. A. A. Yousif, M. E. Elzain, S. A. Mazen, H. H. Sutherland, M. H. Abdalla, and S. F. Mansour, J. Phys. Condens. Matter. 6, 5717 (1994 b).

8. J. Smit and H. P. J. Wijn, "Ferrites", Cleaver-Hume. Press, London, (1959).

9. C. Otero Arean, E. Garcia Diaz, J. M. Rubio Gonzalez and M. A. Villa Garcia, J. Sol. State Chem. 77, 275 (1988).

10. B. Gillot and F. Jemmali, phys. stat. sol. (a) 76, 601 (1983).

11. M. A. Amer, phys. stat. sol. (a) 151, 205 (1995).

12. D. C. Dobson, J. W. Linnet, and M. M. Rahman, J. Phys. Chem. Solids 31, 727 (1970).

13. H. N. Ok, K. S. Baek, H. S. Lee, and C. S. Kim, Phys. Rev. B 41, 62 (1990).

14. M. A. Amer, Hyper. Interact. 131, (2000), 29. 
15. B. J. Evans and S. S. Hafner, J. Phys. Chem. Solids 29, (1968), 1573.

16. M. K. Fayek, F. M. Sayed Ahmed, S. S. Ata-Allah, M. K. Elnimr, and M. F. Mostafa, J. Mater. Sci. 27 (1992) 4813.

17. N. A. Halasa, G. De Pasquali and H. G. Drickamer, Phys. Rev. B 10, (1974) 154.

18. V. I. Nikolaev, V. S. Rusakov and N. I Chistyakova, phys. stat. sol. (a) 91, (1982) K139.

19. T. M. Meaz, M.A. Amer, and C. B. Koch, Hyperfine interactions 156, 465 (2004). 